\title{
əThe Impact of Spatial Resolution, Land Use, and Spinup Time on Resolving Spatial Precipitation Patterns in the Himalayas ${ }^{\mathscr{O}}$
}

\author{
P. N. J. BONEKAMP \\ Department of Physical Geography, Utrecht University, Utrecht, Netherlands \\ E. COLLIER \\ Climate System Research Group, Friedrich-Alexander Universität Erlangen-Nürnberg, Erlangen, Germany \\ W. W. IMMERZEEL \\ Department of Physical Geography, Utrecht University, Utrecht, Netherlands
}

(Manuscript received 7 November 2017, in final form 24 April 2018)

\begin{abstract}
Frequently used gridded meteorological datasets poorly represent precipitation in the Himalayas because of their relatively low spatial resolution and the associated representation of the complex topography. Dynamical downscaling using high-resolution atmospheric models may improve the accuracy and quality of the precipitation fields. However, most physical parameterization schemes are designed for a spatial resolution coarser than $1 \mathrm{~km}$. In this study the Weather Research and Forecasting (WRF) Model is used to determine which resolution is required to most accurately simulate monsoon and winter precipitation, 2-m temperature, and wind fields in the Nepalese Himalayas. Four model nests are set up with spatial resolutions of 25, 5, 1, and $0.5 \mathrm{~km}$, respectively, and a typical 10-day period in summer and winter in 2014 are simulated. The model output is compared with observational data obtained from automatic weather stations, pluviometers, and tipping buckets in the Langtang catchment. Results show that, despite issues with the quality of the observational data due to undercatch of snowfall, the highest resolution of $500 \mathrm{~m}$ does provide the best match with the observations and gives the most plausible spatial distribution of precipitation. The quality of the wind and temperature fields is also improved, whereby the cold temperature bias is decreased. Our results further elucidate the performance of WRF at high resolution and demonstrate the importance of accurate surface boundary conditions and spinup time for simulating precipitation. Furthermore, they suggest that future modeling studies of High Mountain Asia should consider a subkilometer grid for accurately estimating local meteorological variability.
\end{abstract}

\section{Introduction}

High Mountain Asia is sometimes referred to as the Third Pole, since the region hosts the largest reserves of freshwater stored in glaciers and snow outside the polar

¿ Denotes content that is immediately available upon publication as open access.

Supplemental information related to this paper is available at the Journals Online website: https://doi.org/10.1175/JHM-D-170212.s1.

Corresponding author: P. N. J. Bonekamp, p.n.j.bonekamp@ uu.nl regions (Qiu 2008). The region contains approximately $5000 \mathrm{~km}^{3}$ of ice and supplies water for more than 1.5 billion people living downstream, which is approximately $20 \%$ of the world population (Kraaijenbrink et al. 2017; Yao et al. 2012; Immerzeel et al. 2010). Monsoonal precipitation is the largest contributor to the hydrological budget in the Himalayas (Bookhagen and Burbank 2010). The amount of precipitation is controlled by the monsoon circulation, westerly winds, and orographic forcing, where the spatial distribution of precipitation is affected by terrain height, relief, and aspect and by moisture availability (Whiteman 2000). However, since these processes interact with each other and play a role at different scales, it is complex to model precipitation in this region. Additionally, field 
observations, particularly at high altitude, are scarce, and model validation is difficult (e.g., Maussion et al. 2014; Immerzeel et al. 2014, 2015).

Frequently used gridded meteorological datasets poorly represent precipitation in the Himalayas because of their relatively low spatial resolution and the associated representation of the complex topography (Immerzeel et al. 2015). Dynamical downscaling using high-resolution atmospheric models has been found to improve the accuracy and quality of simulated meteorological fields. For example, Dimitrova et al. (2016) found that a grid spacing of $500 \mathrm{~m}$ is better at capturing flows in complex terrain than a $2-\mathrm{km}$ grid spacing. In theory, simulations at higher spatial resolution better resolve the bottom boundary forcing and important valley-scale processes. However, in reality, increasing the spatial resolution does not necessarily lead directly to higher accuracy of the results (Zhang et al. 2013), as specific parameterizations may not be suitable for very high resolution. Horvath et al. (2012) showed that decreasing the grid spacing to $1 \mathrm{~km}$ has the highest accuracy for wind speed and decreasing to $333 \mathrm{~m}$ does not lead to better results. Collier and Immerzeel (2015) investigated the Langtang catchment in Nepal with $1-\mathrm{km}$ resolution and showed the importance of near-kilometer grid spacing for capturing local meteorological variability. However, even at this resolution, significant biases in simulated precipitation remained. Therefore, there is a need to investigate the impact of subkilometer grid spacing on the accuracy of simulated meteorological fields in this region of complex topography.

The mesoscale atmospheric Weather Research and Forecasting (WRF) Model (Skamarock and Klemp 2008) is becoming an established tool for modeling mountainous areas in general and for High Mountain Asia, specifically. Running WRF for mountainous areas with high resolution can help to resolve spatial variability of atmospheric key variables and land-atmosphere exchanges better than larger grid sizes, since heterogeneous surface fluxes and near-surface meteorological parameters are better resolved (Talbot et al. 2012). Maussion et al. (2014) showed that WRF can be used to model different weather systems in the Himalayas, including mountain-induced orographic precipitation at a grid spacing of $10 \mathrm{~km}$. Maussion et al. (2011) used WRF configured with a grid spacing down to $2 \mathrm{~km}$ over the Tibetan Plateau to simulate one month and validated the precipitation with the Tropical Rainfall Measuring Mission (TRMM) dataset and the snow extent with the Moderate Resolution Imaging Spectroradiometer (MODIS) dataset. Results show WRF simulates snow and rainfall for that period in reasonable agreement with observations. However, previous studies with WRF have shown that simulations are sensitive to the spinup time (Román-Cascón et al. 2016; Wang et al. 2012). In general, numerical atmospheric prediction models require spinup time when there is no data assimilation applied. Spinup time allows the model to adjust from the initial conditions to a state that is consistent with its own numerics and physics and to develop appropriate largescale circulations (Jankov et al. 2007; Skamarock 2004). To prevent instabilities in WRF, the spinup time should be at least $12 \mathrm{~h}$ (Jankov et al. 2007) and likely depends on the quality of the model input and the condition of the soil fields (Kleczek et al. 2014). The spinup time influences the initial conditions such as the soil moisture content and therefore the latent heat flux, which in turn influences the precipitation. In addition, the default land use data have been found to be suboptimal for the central Himalayas, with the forested area in the Langtang catchment underestimated by $60 \%$ (Collier and Immerzeel 2015). The land use likely has a significant effect on the model results, since it controls the exchange of heat and momentum between the land and air (e.g., Cheng et al. 2013). Therefore, the impact of the grid spacing, land use, and spinup time need to be assessed.

In this study, we use the WRF Model to investigate the role of subkilometer grid spacing and the representation of land surface heterogeneity on simulated precipitation in the Langtang catchment, located in the Nepalese Himalayas. The aim of this research is to determine an optimal spatial resolution for modeling key atmospheric variables in high-altitude catchments, as a compromise between the agreement with observations and computational time. We also investigate the effects of spinup time and land use on the atmospheric variables by testing a range of starting dates for two 10-day simulations during the monsoon and winter periods and by introducing a new land use dataset in WRF. The results of the simulations are compared to observational data obtained from automatic weather stations (AWSs), pluviometers, and tipping buckets (TBs) located in the Langtang catchment.

\section{Methods}

\section{a. Study area}

The Langtang catchment is located in the central Hindu Kush-Himalaya region, $100 \mathrm{~km}$ north of Kathmandu (Nepal), and has an area of $584 \mathrm{~km}^{2}$, including $140 \mathrm{~km}^{2}$ of glacier area, of which $40 \%$ is covered in debris (Collier and Immerzeel 2015). The catchment has a steep topographic gradient and ranges in elevation from 1406 up to $7180 \mathrm{~m}$ above sea level. Most precipitation 
events occur during the monsoon period (JuneSeptember), while in winter precipitation is produced by passing low pressure systems. The relation between precipitation and topography in the catchment varies throughout the year and depends on the large-scale circulation in combination with mesoscale orographic and thermal-induced circulations (Collier and Immerzeel 2015).

\section{b. Simulation period and measurements}

Since different meteorological processes play a role in winter and summer, we selected two representative simulation periods for the numerical experiments: one typical winter period including a precipitation event (10-20 February 2014) and one monsoon period (1828 July 2014). These periods were selected by checking the available observations of precipitation and were found to be representative of the winter and summer, respectively (i.e., no extreme events when looking at adjacent years). For the winter period we selected the period such that a typical winter precipitation event is included, and for the summer period we selected a period with a typical monsoon daily rainfall regime. The observation stations used for validation of WRF for both the winter and summer periods are listed in Table 1 . We note that the number of stations is different for the observations of precipitation, temperature, and wind speed. For details and quality checks of the sensors, see Immerzeel et al. (2014). Comparison between the measurements and the simulation is based on the closest grid point to the coordinates of the measurement station, without correcting for differences between the real and modeled elevation.

\section{c. Model}

The advanced research WRF Model v3.8.1 is used for the numerical experiments described in the following section. This model is a mesocale nonhydrostatic numerical weather prediction model and can be used for both operational weather forecasting applications as well for atmospheric research. In this research, we use the configuration of Collier and Immerzeel (2015), and the model settings are listed in Table 2. Four nested domains are used in each numerical experiment, configured with horizontal grid spacings of $25,5,1$, and $0.5 \mathrm{~km}$, which we refer to as D1, D2, D3, and D4, respectively (Fig. 1). For D1 and D2, 2-arc-min $(\approx 3700 \mathrm{~m}$ at the equator) input topography is used, while in D3 and D4 3-arc-s ( $\approx 90 \mathrm{~m}$ at the equator) data are used, which are resampled to the respective domain resolutions during preprocessing. The model results were reproducible with a higher number of vertical levels (65 layers) and indicate 50 vertical layers are sufficient
TABLE 1. Available observation stations for both the winter (W) and summer (S) event (for each period, a check indicates data were available whereas an $\mathrm{X}$ means data were not available). The AWSs measure precipitation, air temperature, relative humidity, snow depth, and wind speed; the pluviometer (Pluvio) measures precipitation, air temperature, and relative humidity; and the TBs only measure precipitation.

\begin{tabular}{llccccc}
\hline \hline & \multicolumn{1}{c}{ Station } & W & S & Lat & Lon & Height $(\mathrm{m})$ \\
\hline AWS & 1. Yala & $\checkmark$ & $\checkmark$ & 28.23230 & 85.60967 & 5090 \\
& 2. Kyanging & $\checkmark$ & $\checkmark$ & 28.21081 & 85.56948 & 3862 \\
Pluvio & 3. Yala & $\checkmark$ & $\checkmark$ & 28.22900 & 85.59700 & 4831 \\
& 4. Gangja La & X & $\checkmark$ & 28.18625 & 85.56961 & 4361 \\
& 5. Langshisha & $\checkmark$ & $\checkmark$ & 28.20265 & 85.68619 & 4452 \\
& 6. Morimoto & X & $\checkmark$ & 28.25296 & 85.68152 & 4919 \\
TB & 7. TB2 & $\checkmark$ & $\checkmark$ & 28.16212 & 85.43073 & 2370 \\
& 8. TB3 & $\checkmark$ & $\checkmark$ & 28.21398 & 85.52745 & 3539 \\
& 9. TB5 & $\checkmark$ & $\checkmark$ & 28.19558 & 85.61304 & 3875 \\
& 10. TB7 & $\checkmark$ & $\checkmark$ & 28.23027 & 85.55958 & 4141 \\
& 11. TB8 & $\checkmark$ & $\checkmark$ & 28.21760 & 85.66306 & 4312 \\
& 12. TB9 & $\checkmark$ & $\checkmark$ & 28.20265 & 85.68619 & 4452 \\
& 13. TB14 & $\checkmark$ & $\checkmark$ & 28.20216 & 85.64315 & 3974 \\
& 14. TB15 & $\checkmark$ & $\checkmark$ & 28.24014 & 85.69743 & 4617 \\
\hline
\end{tabular}

in the experiments. The model configuration is the same for both the winter and the summer periods, such that in future studies multiannual model runs can be performed with a single configuration. The model settings for these domains are listed in Table 2 and are based on the study of Collier and Immerzeel (2015) and several additional tests. Differences from the configuration used in the previous study include the planetary boundary layer (PBL) scheme and the radiation scheme. The Yonsei University (YSU) PBL scheme was used in all four domains, since it includes an option to correct the high wind speed bias in WRF. PBL parameterizations can be used when the scale of large turbulent eddies is much smaller than the scale of the spatial grid. The terra incognita (Wyngaard 2004) is located between the PBL and large-eddy simulation (LES) range, in which the dominant length scale of the flow is comparable to the grid spacing (roughly between $1 \mathrm{~km}$ and $100 \mathrm{~m}$ ). Hong and Dudhia (2012) show that PBL schemes may work down to 500-m grid spacing. In addition, LES requires a grid spacing smaller than $100 \mathrm{~m}$ to resolve convective boundary layer eddies (Arnold et al. 2012). Therefore, we chose to include a PBL parameterization in D4. As forcing for the lateral boundaries, 6-hourly ERA-Interim data $\left(0.75^{\circ} \times 0.75^{\circ}\right)$ are used (Dee et al. 2011), and we employ one-way nesting.

\section{d. Numerical experiments}

The land use controls the latent heat flux and therefore the moisture content in the air and local precipitation as a consequence. The default land use dataset in WRF is not representative for the Langtang region, 
TABLE 2. Overview of the WRF configuration.

Horizontal grid spacing

Grid dimensions

Vertical levels

Time step

Model top pressure

Nesting approach

Microphysics

Planetary boundary layer

Land surface

Cumulus

Radiation

Surface layer

Slope/shadowing effects

Top boundary condition

Diffusion

Lateral boundary forcing
Domain configuration

\begin{tabular}{l}
\hline $25,5,1,0.5 \mathrm{~km}$ \\
$125 \times 105,111 \times 111,171 \times 171,121 \times 121$ \\
50 \\
$50,10,1,0.2 \mathrm{~s}$ \\
$50 \mathrm{hPa}$ \\
One way
\end{tabular}

Model physics

\section{Morrison}

YSU (topo_wind = 1)

Noah-MP

Kain-Fritsch scheme (only in D1)

RRTM for GCMs

MM5 similarity scheme

Zängl

Morrison et al. (2009)

Hong et al. (2006)

Niu et al. (2011)

Kain (2004)

Iacono et al. (2008)

Paulson (1970)

Zängl (2002) since the amount of forest area is underestimated and the glacier outlines are not correct (Collier and Immerzeel 2015). Therefore, the land use map of the Food and Agriculture Organization (FAO) of the United Nations (FAO 2017) is used in this research. Important differences between the default and new land use include the increase in forest $(16 \%)$ and glacierized area $(2 \%)$. The default and FAO land use datasets used for D3 and D4 are shown in Fig. 2.

In our simulations we investigate the influence of spinup times ranging from $12 \mathrm{~h}$ to 5 days in length on the 2-m air temperature, 10-m wind speed, and amount of precipitation in $\mathrm{D} 3$.
An overview of the numerical experiments performed in this paper is given in Table 3. These experiments are performed for both the winter and summer period on the Dutch supercomputer Cartesius. Simulating a 10-day period typically takes 2 days to complete while running on 192 processors.

\section{e. Statistical evaluation}

To evaluate the simulated 2-m air temperature, $10-\mathrm{m}$ wind speed, and amount of precipitation with the observations, several statistical techniques are used: the Pearson correlation coefficient, mean, bias, and root-mean-square error (RMSE). We compute these
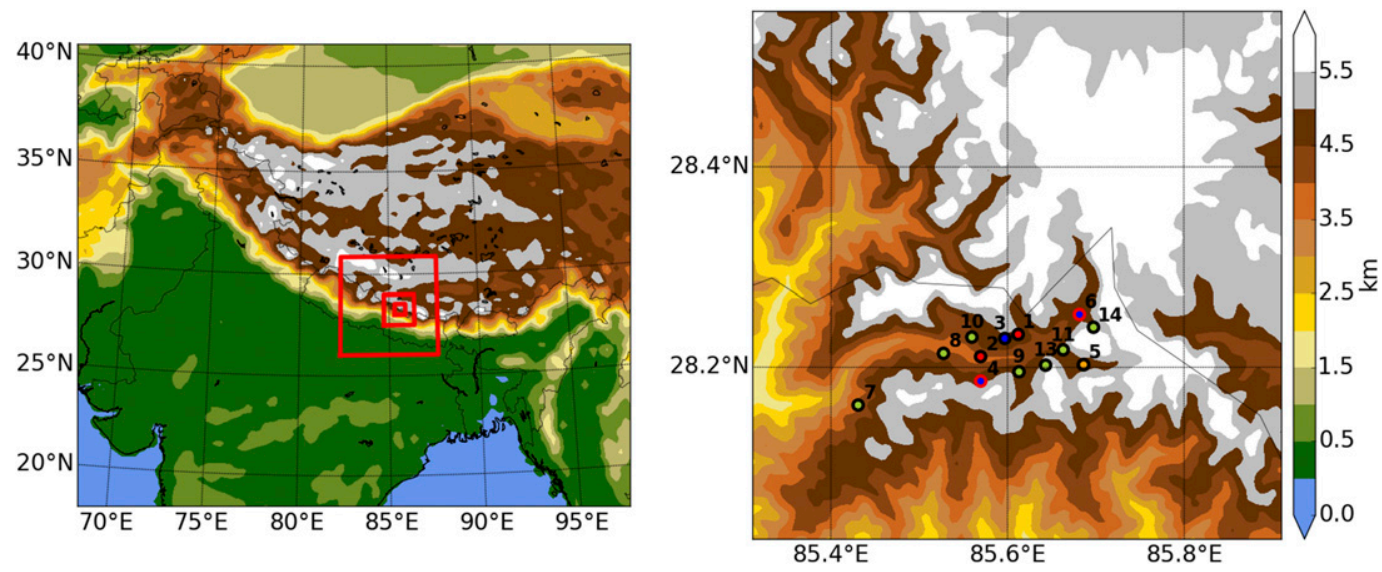

FIG. 1. (left) The topography and locations of each domain. (right) The topography in D4 and the locations of the measurement stations are shown: eight TBs (green), two AWSs (red), and four pluviometers (blue). The orange point is the place were both a TB and a pluviometer are located. A black edge means the station is used for both the winter and summer periods; a red edge means the station is only used for the summer period. The numbers correspond to the numbers in Table 1 . The black contour line is the country border of Nepal with China. 

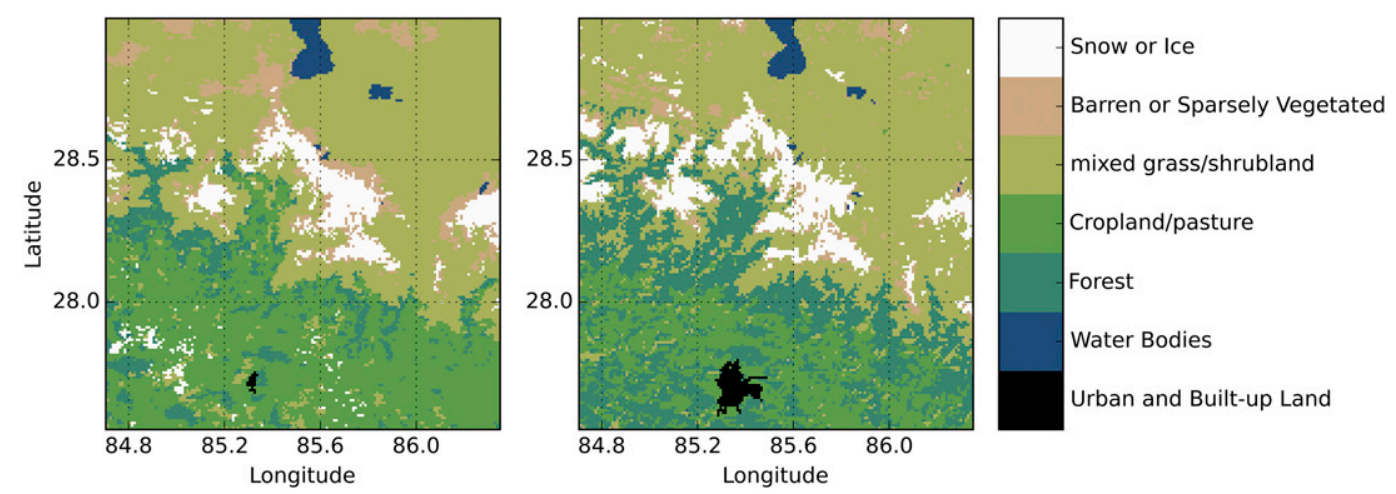

FIG. 2. The (left) default and (right) FAO-defined land use in WRF.

quantities at each station and report the average value over all stations for model evaluation. To assess the correctness of the timing of the simulated events, we make use of the Rousseau index (RI; Rousseau 1980), which is expressed as

$$
\frac{\mathrm{SO} \times \mathrm{NSNO}-\left(\frac{\mathrm{NSO}+\mathrm{SNO}}{2}\right)^{2}}{\left(\mathrm{SO}+\frac{\mathrm{NSO}+\mathrm{SNO}}{2}\right) \times\left(\mathrm{NSNO}+\frac{\mathrm{NSO}+\mathrm{SNO}}{2}\right)} .
$$

Each precipitation event for each time step is categorized into one of the four categories: SO, NSO, SNO, and NSNO, where SO is the amount of events when precipitation is simulated and also observed, NSO when the event is not simulated but observed, SNO when the event is simulated but not observed, and NSNO when no precipitation is simulated and also not observed. In case of SO and NSNO, the simulation is consistent with the observation, and when NSO or SNO occurs there is a mismatch between the model and the observations. RI has a value between -1 and 1 where the model fully agrees with the measurements if $\mathrm{RI}=1$.

\section{f. Snow correction factor}

Solid precipitation is hard to monitor since the gauge geometry can induce systematic errors due to wind flow. The airflow around a gauge is disturbed, whereby undercatch of snow increases with increasing wind speed. Several studies try to quantify the amount of undercatch of snow (e.g., Thériault et al. 2012; Goodison et al. 1998). In this study, we use the dry and mean theoretical relationship derived from Thériault et al. (2012) to show the effect and range of the amount of undercatch, which is highly dependent on the snow type. We assume the precipitation type is snow if $T_{\text {air }}<0^{\circ} \mathrm{C}$ (Liu and Chen 2016) and test two different assumptions about the liquid water content of snow to see the effect on the undercatch of snow. The relationships (Thériault et al. 2012) between the collection efficiency $C$ and wind speed $U$ for a mixture of wet and dry snow and dry snow are

Mixture:

$$
\begin{aligned}
U<2.0 \mathrm{~m} \mathrm{~s}^{-1}, & C=1.0-0.01 U, \\
2.0 \leq U<7.0 \mathrm{~m} \mathrm{~s}^{-1}, & C=1.3-0.16 U, \quad \text { and } \\
U \geq 7.0 \mathrm{~m} \mathrm{~s}^{-1}, & C=0.18 .
\end{aligned}
$$

Dry:

$$
\begin{array}{ll}
U<2.0 \mathrm{~m} \mathrm{~s}^{-1}, & C=1.0-0.01 U, \\
2.0 \leq U<5.0 \mathrm{~m} \mathrm{~s}^{-1}, & C=1.6-0.32 U, \quad \text { and } \\
U \geq 5.0 \mathrm{~m} \mathrm{~s}^{-1}, & C=0.18 .
\end{array}
$$

\section{Results and discussion}

\section{a. Land use}

In Fig. 3 the effect of the new land use on the total and solid precipitation is shown for both the winter and summer periods. Land use influences the total accumulated precipitation by describing the surface characteristics

TABLE 3. Overview of performed numerical experiments. All experiments include D1, D2, D3, and D4 and are run for both the summer and winter period.

\begin{tabular}{llc}
\hline \hline Name & Land use & Spinup time \\
\hline DEF & Default & 1 day \\
EXP1 & FAO & $12 \mathrm{~h}$ \\
EXP2 & FAO & 1 day \\
EXP3 & FAO & 3 days \\
EXP4 & FAO & 5 days \\
\hline
\end{tabular}



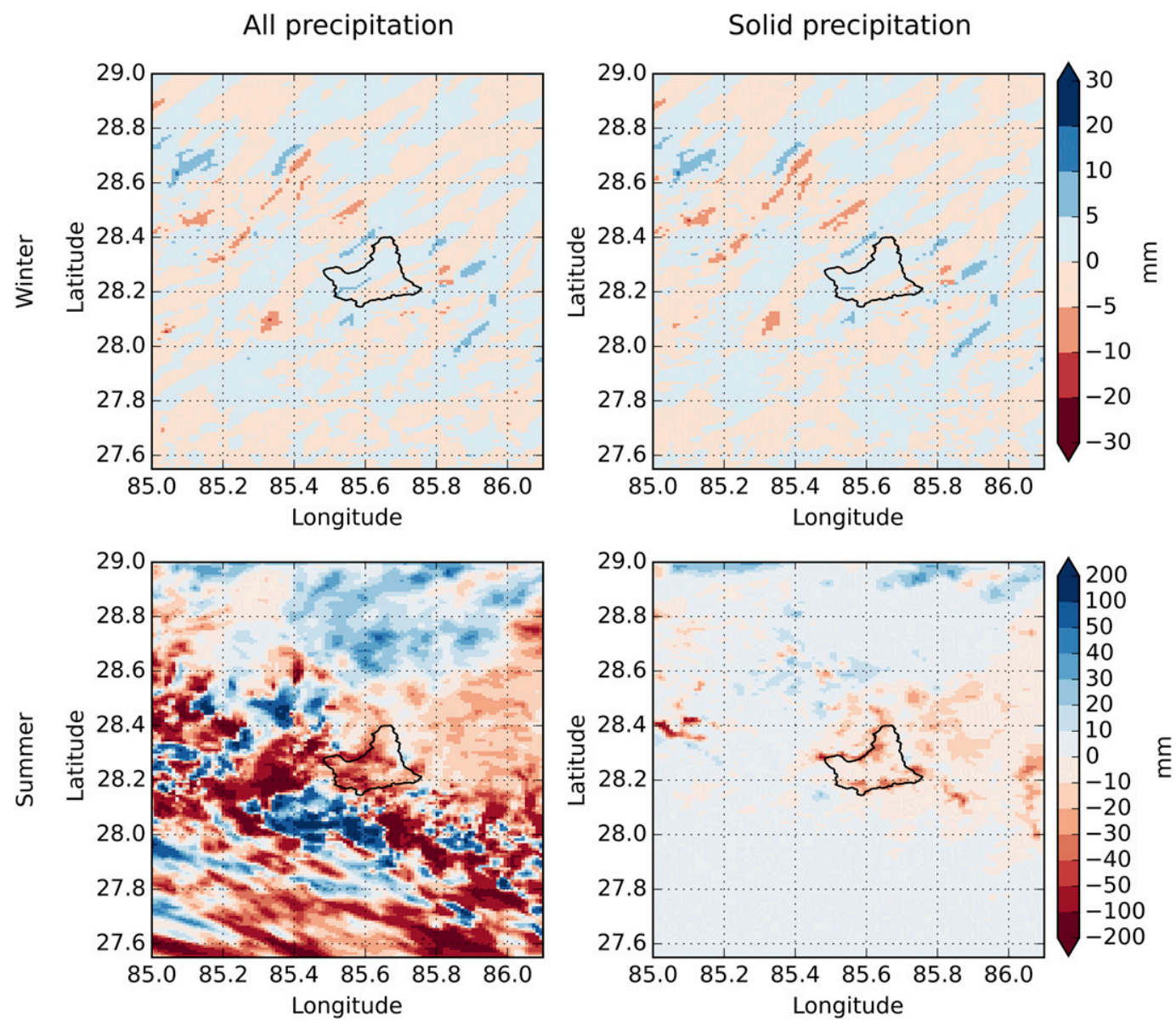

FIG. 3. Effect of the FAO land use (the difference between the model results using the FAO and default land use) on the amount of (left) total and (right) solid accumulated precipitation over 10 days for both the (top) winter and (bottom) summer for D3. The black contour indicates the catchment outline. The glacierized areas are visible in Fig. 2, and the topography of the domain is in Fig. 1.

that affect the surface energy balance and the moisture budget. The amount of vegetation affects the latent heat flux and therefore clouds and precipitation, and it also affects the surface temperature and therefore sensible heat flux, lower atmospheric stability, and turbulence. For example, the effect of the FAO land use is stronger in summer than in winter, since there is a more humid environment (monsoon) compared to the winter period. The latent heat flux in summer is 4.5 times larger than in winter averaged over D3. Second, important weather processes are valley-scale driven in summer while in winter they are acting on the synoptic scale.

In summer the surface moisture flux and precipitation averaged over the whole domain (catchment) are $2 \%$ $(6 \%)$ and $10 \%(16.9 \%)$ lower with the FAO land use compared to the default land use dataset in WRF. The reductions in the moisture flux and precipitation are comparable in value, which indicates they are highly related. In summer the dominant precipitation type is rain, but at higher altitudes snow is also present. The decreased snowfall in summer is clearly visible above the glacierized areas and is caused by the general drying trend by the FAO land use, which affects both the solid and liquid precipitation. The surface moisture flux is less pronounced south of the catchment with the FAO land use and contributes to the decrease in precipitation in that region. The decrease in precipitation north of the catchment is consistent with lower wind speeds in the surrounding high-elevation regions. As a result, less moisture is advected into this region, and therefore less moisture is available (see the online supplementary material). In winter almost all precipitation falls as snow and is not as clearly distributed as in the summer period. Winter precipitation patterns are comparable when using the FAO land use dataset, and the total amount of precipitation stayed the same in the domain (both $4.9 \mathrm{~mm} \mathrm{day}^{-1}$ ), which indicates that the latent heat flux is the main driver of the change in locally driven 
TABLE 4. Statistics of different spinup times for the 10-m wind speed, 2-m air temperature, and precipitation in D3, based on 3-hourly averaged data (WRF output was available for every hour). All values compare the simulation to the measurements and are the mean of all available stations. The accumulated precipitation, mean temperature, and mean wind speed were $14 \mathrm{~mm}(133 \mathrm{~mm}),-7.1^{\circ} \mathrm{C}\left(6.0^{\circ} \mathrm{C}\right)$, and $3.8 \mathrm{~m} \mathrm{~s}^{-1}\left(2.1 \mathrm{~m} \mathrm{~s}^{-1}\right)$, respectively, for winter (summer) period. A single asterisk indicates $p<0.01$, and two asterisks indicate $p<0.05$

\begin{tabular}{|c|c|c|c|c|c|c|c|c|c|c|}
\hline & \multicolumn{5}{|c|}{ Winter } & \multicolumn{5}{|c|}{ Summer } \\
\hline & DEF & EXP1 & EXP2 & EXP3 & EXP4 & $\mathrm{DEF}$ & EXP1 & EXP2 & EXP3 & EXP4 \\
\hline \multicolumn{11}{|c|}{ Precipitation } \\
\hline$r$ & $0.37 *$ & $0.35 *$ & $0.38 *$ & $0.33 *$ & $0.33^{*}$ & 0.21 & $0.23 * *$ & $0.30 *$ & 0.09 & 0.20 \\
\hline RMSE (mm) & 2.0 & 2.0 & 2.1 & 2.0 & 2.1 & 3.5 & 3.3 & 2.9 & 2.8 & 2.7 \\
\hline Bias (\%) & 281 & 297 & 287 & 284 & 290 & 456 & 333 & 339 & 358 & 350 \\
\hline Total $(\mathrm{mm})$ & 74 & 74 & 76 & 70 & 72 & 165 & 119 & 135 & 118 & 146 \\
\hline \multicolumn{11}{|c|}{ 2-m air temperature } \\
\hline$r$ & $0.82 *$ & $0.81 *$ & $0.81 *$ & $0.81 *$ & $0.81 *$ & 0.85 & $0.85^{* *}$ & $0.85 *$ & 0.87 & 0.85 \\
\hline RMSE $\left({ }^{\circ} \mathrm{C}\right)$ & 8.0 & 8.0 & 8.2 & 8.3 & 8.5 & 2.5 & 2.6 & 2.6 & 2.6 & 2.6 \\
\hline $\operatorname{Bias}\left({ }^{\circ} \mathrm{C}\right)$ & 7.6 & 7.7 & 7.9 & 8.0 & 8.2 & 2.4 & 2.5 & 2.5 & 2.3 & 2.5 \\
\hline Mean $\left({ }^{\circ} \mathrm{C}\right)$ & -14.7 & -14.8 & -15.0 & -15.1 & -15.2 & 3.6 & 3.5 & 3.6 & 3.5 & 3.6 \\
\hline \multicolumn{11}{|c|}{ 10-m wind speed } \\
\hline$r$ & $0.47 *$ & $0.43^{*}$ & $0.46^{*}$ & $0.45^{*}$ & $0.43^{*}$ & 0.56 & $0.41 * *$ & $0.51^{*}$ & 0.46 & 0.40 \\
\hline $\operatorname{RMSE}\left(\mathrm{m} \mathrm{s}^{-1}\right)$ & 3.5 & 3.5 & 3.3 & 3.3 & 3.4 & 1.3 & 1.3 & 1.2 & 1.4 & 1.5 \\
\hline $\operatorname{Bias}\left(\mathrm{m} \mathrm{s}^{-1}\right)$ & 2.9 & 2.7 & 2.6 & 2.6 & 2.6 & 1.0 & 1.0 & 0.9 & 1.03 & 1.2 \\
\hline $\operatorname{Mean}\left(\mathrm{m} \mathrm{s}^{-1}\right)$ & 6.4 & 6.2 & 6.1 & 5.9 & 6.0 & 3.0 & 2.8 & 2.7 & 2.9 & 3.0 \\
\hline
\end{tabular}

precipitation in summer. The temperature differences are negligible $\left(<0.05^{\circ} \mathrm{C}\right.$ averaged over D3) in both seasons, which means that the drying effect of the FAO land use does not result in higher temperatures. However, locally temperature differences range from $-4.2^{\circ}$ to $2.7^{\circ} \mathrm{C}$.

In Table 4 an overview of statistics for the default (DEF) and FAO (EXP2) land use is given. All values in that table are an average for the observation stations mentioned in Table 1, and all statistics are calculated compared to the observations. Indeed, the largest differences can be found in the statistics of summer precipitation, and the total accumulated precipitation is reduced to $135 \mathrm{~mm}$ ( $165 \mathrm{~mm}$ by the default land use), whereby it is in closer agreement with the observations $(133 \mathrm{~mm})$. In winter the differences in statistics for precipitation, temperature, and wind speed between the two land uses are small and are likely due to the low moisture flux, as discussed above. The FAO land use represents the total accumulated summer precipitation better than the default land use dataset and will be used in upcoming experiments.

\section{b. Spinup time}

The temporal evolution of the precipitation averaged over the catchment for the spinup experiments is shown in Fig. 4. During the winter period, the precipitation amount and timing do not differ significantly between the different spinup times, unlike in summer. During the monsoon, precipitation is driven locally, hence the correct representation of, for example, soil moisture, and therefore spinup time is important. In winter synoptic disturbances drive precipitation, and therefore the winter is less sensitive to the spinup time. In Table 4 an overview of statistics for the spinup time experiments is given. Small differences can be found between the different spinup times in winter for the accumulated precipitation (between 70 and $76 \mathrm{~mm}$ ), averaged temperature (between $-15.2^{\circ}$ and $-14.8^{\circ} \mathrm{C}$ ) and averaged wind speed (between 5.9 and $6.2 \mathrm{~m} \mathrm{~s}^{-1}$ ). In the summer period, the average temperature and wind speed are also comparable between the experiments: between $3.5^{\circ}$ and $3.6^{\circ} \mathrm{C}$ and between 2.7 and $3.0 \mathrm{~m} \mathrm{~s}^{-1}$, respectively. Kleczek et al. (2014) found that above flat terrain a spinup time longer than $24 \mathrm{~h}$ decreases the wind speed bias but increases the negative temperature bias, but our results do not confirm this trend. The amount of precipitation is extremely sensitive to the spinup time in summer and does not show a clear trend with increasing spinup time. Correlations with observations based on 3-hourly data vary between 0.1 and 0.3 , while accumulated precipitation varied from 118 and $146 \mathrm{~mm}$. The spinup time influences the timing and amount of precipitation, and in lesser amounts, the temperature and wind speed (Table 4). An increase in the quality of the statistics can be seen when increasing the spinup time from 12 to $24 \mathrm{~h}$, especially in the amount of accumulated precipitation in summer, but not for longer spinup times (Table 4). Therefore, a spinup time of $24 \mathrm{~h}$ is chosen for subsequent simulations. 

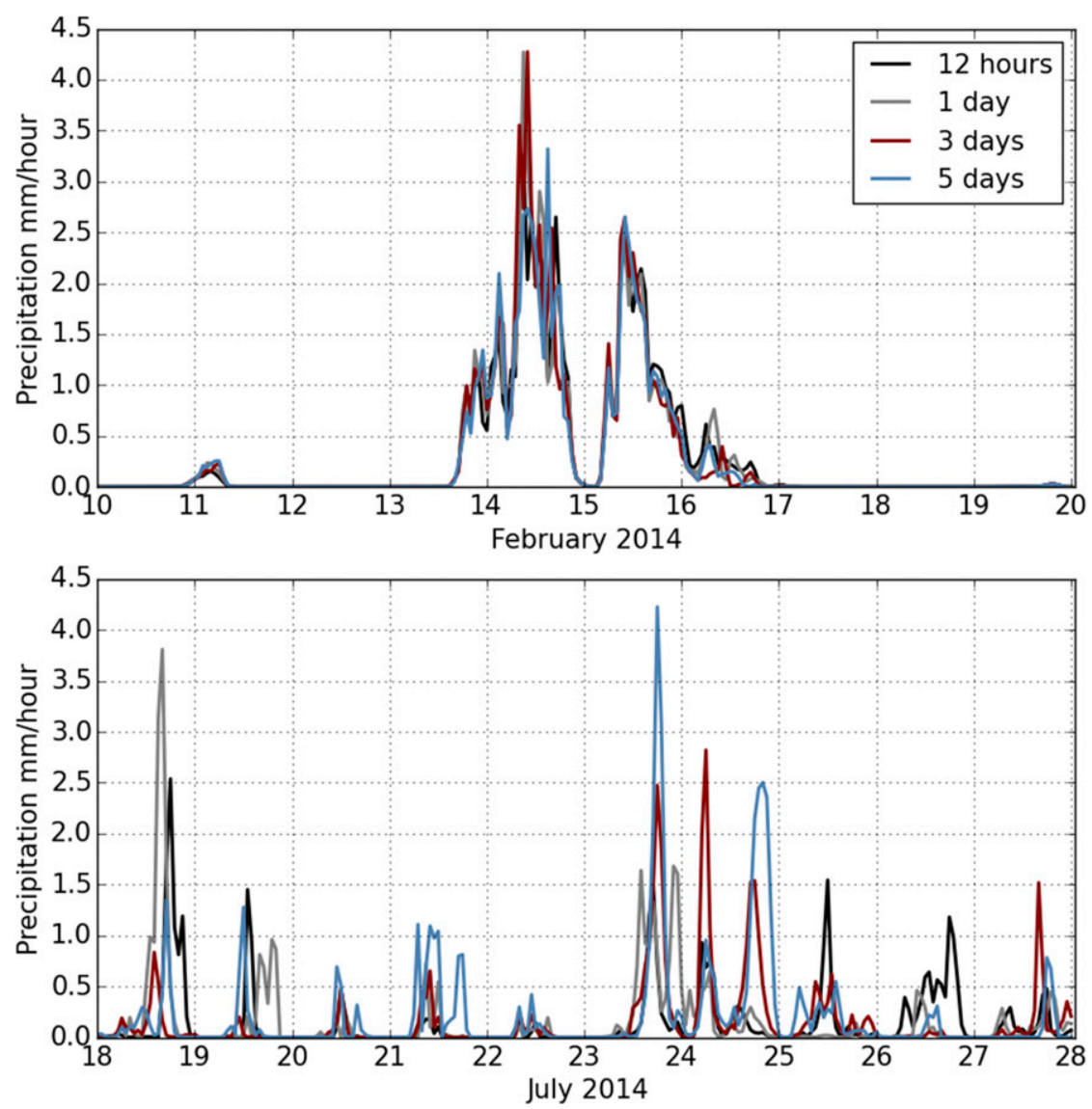

FIG. 4. The hourly precipitation averaged over all grid cells in the catchment for the different spinup times (12 h and 1, 3, and 5 days) for the (top) winter and (bottom) summer.

\section{c. Spatial resolution}

Increasing the spatial resolution has a positive effect on the model results. Figure 5 shows the accumulated precipitation over the winter (top row) and summer period (bottom row) for the four domains. Statistics of the accumulated precipitation, 2-m air temperature, and wind speed at the measurement stations (Table 5) show improvement when increasing the spatial resolution. For the temperature and wind speed, the RMSE, bias, and mean are improved, and the correlation coefficient improved or stayed the same as in D3. For precipitation, correlations stayed the same, and the RMSE, bias, and total precipitation did not show a clear improvement (only RMSE and bias increased for the summer period). Precipitation, however, is more spatially variable than wind speed and temperature. The spatial differences in accumulated precipitation between D3 and D4 for the summer and winter period are shown in Fig. 6. In winter the locations with the precipitation maxima in D3 are intensified in D4. In D4 more precipitation is present along steep slopes, since precipitation is orographically forced and the topography is better resolved in this domain. The higher resolution leads to stronger simulated updrafts and accounts for more precipitation at higher elevations. When katabatic winds and valley winds collide, they can lead to strong mixing and therefore to short-lived and intense sporadically turbulent events (Dimitrova et al. 2014). The 95th percentile of the vertically averaged vertical velocity increases by $15 \%$ in D 4 compared to D 3 and could be due to a better representation of the topography but could also be an artifact of instabilities in WRF. On average the vertical velocities are in agreement with other studies (e.g., Reinert and Wirth 2009; Giovannini et al. 2014). The orographic influence on the temperature and wind speed patterns becomes more apparent and glaciers and mountain ridges are better resolved with decreasing grid size (see Figs. 7, 8). We hypothesize that the improved total accumulated precipitation at higher elevations is caused by these better-resolved vertical winds, and we agree with Rasmussen et al. (2011), who found that increasing the spatial resolution results in more snowfall at mountain peaks instead of evenly distributed patterns due to better 

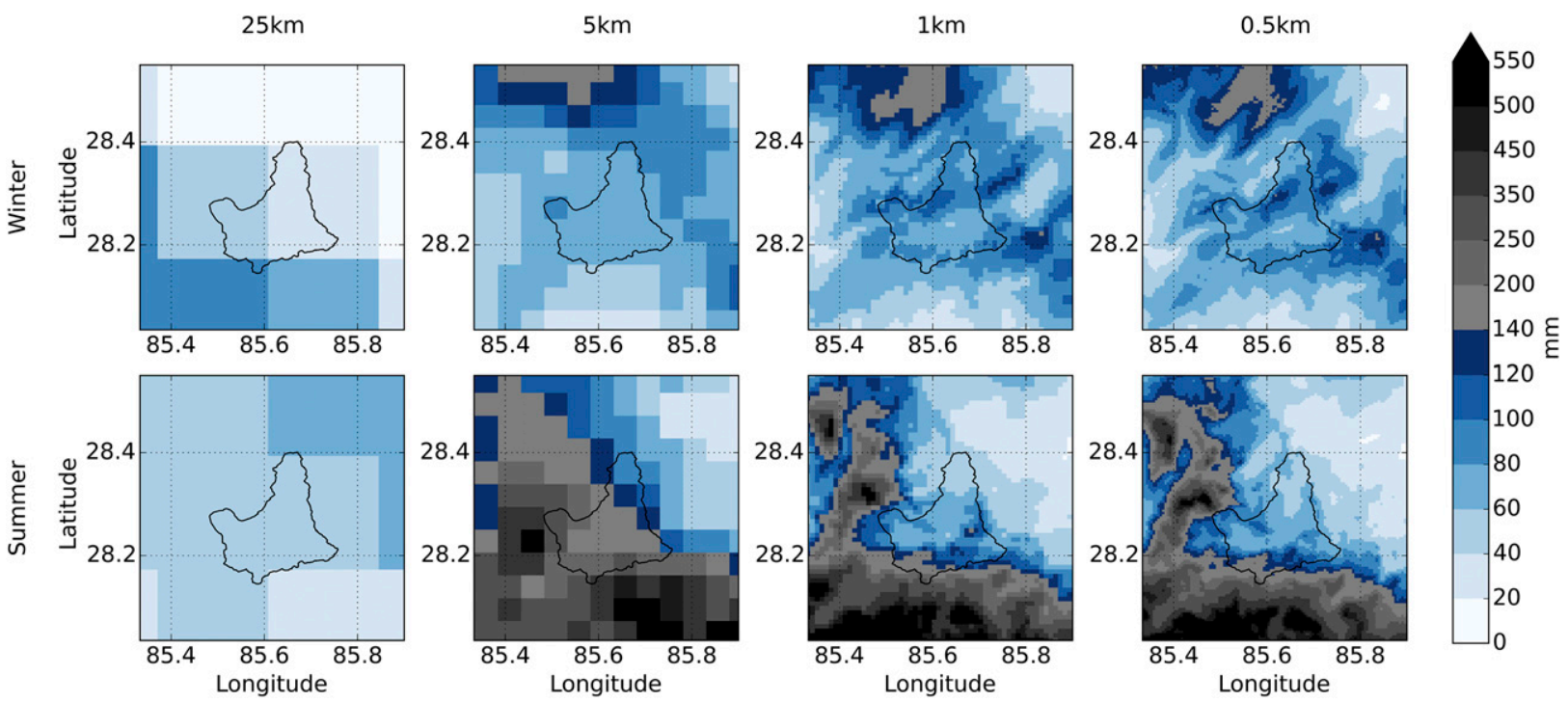

FIG. 5. (from left to right) Accumulated precipitation for D1, D2, D3, and D4. These results are from EXP2 for the (top) winter and (bottom) summer period. Note the precipitation band in D1 is outside the shown area. The black contour indicates the catchment outline. The D1, D2, and D3 panels are cut to the extent of D4. The topography of the domain is visible in Fig. 1.

and narrower simulated updrafts in WRF. Another significant improvement is the strong reduction in temperature bias by $3.0^{\circ} \mathrm{C}$ with increasing resolution from $\mathrm{D} 3$ to $\mathrm{D} 4$ during the winter period (Table 5), likely caused by the better-resolved topography and corresponding wind fields. The mean wind velocity at the stations in winter decreases from $6.1 \mathrm{~m} \mathrm{~s}^{-1}$ in D3 to $3.5 \mathrm{~m} \mathrm{~s}^{-1}$ in D4 and leads to less cooling of the air. In the summer period decreasing the grid spacing from $1 \mathrm{~km}$ to $500 \mathrm{~m}$ leads to higher correlations between observed and simulated precipitation, while in winter the improvement is not observed and is likely caused by the uneven distribution of the observations by elevation.

Correlations between the simulations and the observations of precipitation are relatively low, which is common for WRF simulations in the Himalayas (e.g., Ochoa et al. 2014; Norris et al. 2017). Ochoa et al. (2014)

TABLE 5. Statistics of different spatial resolutions for the 10-m wind speed, $2-\mathrm{m}$ air temperature, and precipitation. All values compare the simulation to the measurements, are 3-hourly averaged, and are the mean of all available stations. The accumulated precipitation, mean temperature, and mean wind speed were $14 \mathrm{~mm}(133 \mathrm{~mm}),-7.1^{\circ} \mathrm{C}\left(6.0^{\circ} \mathrm{C}\right)$, and $3.8 \mathrm{~m} \mathrm{~s}^{-1}\left(2.1 \mathrm{~m} \mathrm{~s}^{-1}\right)$, respectively, for winter (summer) period. The mean observed station height is $4200 \mathrm{~m}$, while the mean modeled station heights are $4893,5049,4883$, and $4739 \mathrm{~m}$ for D1-D4, respectively. An asterisk indicates $p<0.01$.

\begin{tabular}{|c|c|c|c|c|c|c|c|c|}
\hline & \multicolumn{4}{|c|}{ Winter } & \multicolumn{4}{|c|}{ Summer } \\
\hline & D1 & D2 & D3 & D4 & D1 & D2 & D3 & $\mathrm{D} 4$ \\
\hline \multicolumn{9}{|c|}{ Precipitation } \\
\hline$r$ & 0.21 & $0.36^{*}$ & $0.38 *$ & $0.38 *$ & -0.06 & 0.19 & $0.30 *$ & $0.34 *$ \\
\hline RMSE (mm) & 0.3 & 2.0 & 2.1 & 2.20 & 2.9 & 4.2 & 2.9 & 2.7 \\
\hline Bias (\%) & 36 & 279 & 287 & 295 & 416 & 547 & 339 & 290 \\
\hline Total (mm) & 2 & 73 & 76 & 79 & 76 & 192 & 135 & 120 \\
\hline \multicolumn{9}{|c|}{ 2-m air temperature } \\
\hline$r$ & 0.60 & $0.79 *$ & $0.81 *$ & $0.84 *$ & 0.78 & 0.83 & $0.85^{*}$ & $0.86^{*}$ \\
\hline $\operatorname{RMSE}\left({ }^{\circ} \mathrm{C}\right)$ & 9.7 & 9.4 & 8.2 & 5.3 & 2.2 & 3.5 & 2.6 & 1.6 \\
\hline $\operatorname{Bias}\left({ }^{\circ} \mathrm{C}\right)$ & 7.9 & 8.9 & 7.9 & 4.8 & 1.9 & 3.3 & 2.5 & 1.5 \\
\hline Mean $\left({ }^{\circ} \mathrm{C}\right)$ & -14.9 & -16.0 & -15.0 & -12.0 & 6.4 & 2.7 & 3.6 & 4.6 \\
\hline \multicolumn{9}{|c|}{ 10-m wind speed } \\
\hline$r$ & 0.44 & $0.19 *$ & $0.46^{*}$ & $0.49 *$ & 0.64 & 0.26 & $0.51 *$ & $0.72 *$ \\
\hline $\operatorname{RMSE}\left(\mathrm{m} \mathrm{s}^{-1}\right)$ & 1.6 & 6.2 & 3.3 & 1.5 & 1.0 & 1.3 & 1.2 & 0.8 \\
\hline $\operatorname{Bias}\left(\mathrm{m} \mathrm{s}^{-1}\right)$ & 1.3 & 5.2 & 2.6 & 1.1 & 0.8 & 1.0 & 0.9 & 0.6 \\
\hline $\operatorname{Mean}\left(\mathrm{m} \mathrm{s}^{-1}\right)$ & 3.3 & 8.9 & 6.1 & 3.5 & 1.4 & 2.5 & 2.7 & 1.7 \\
\hline
\end{tabular}



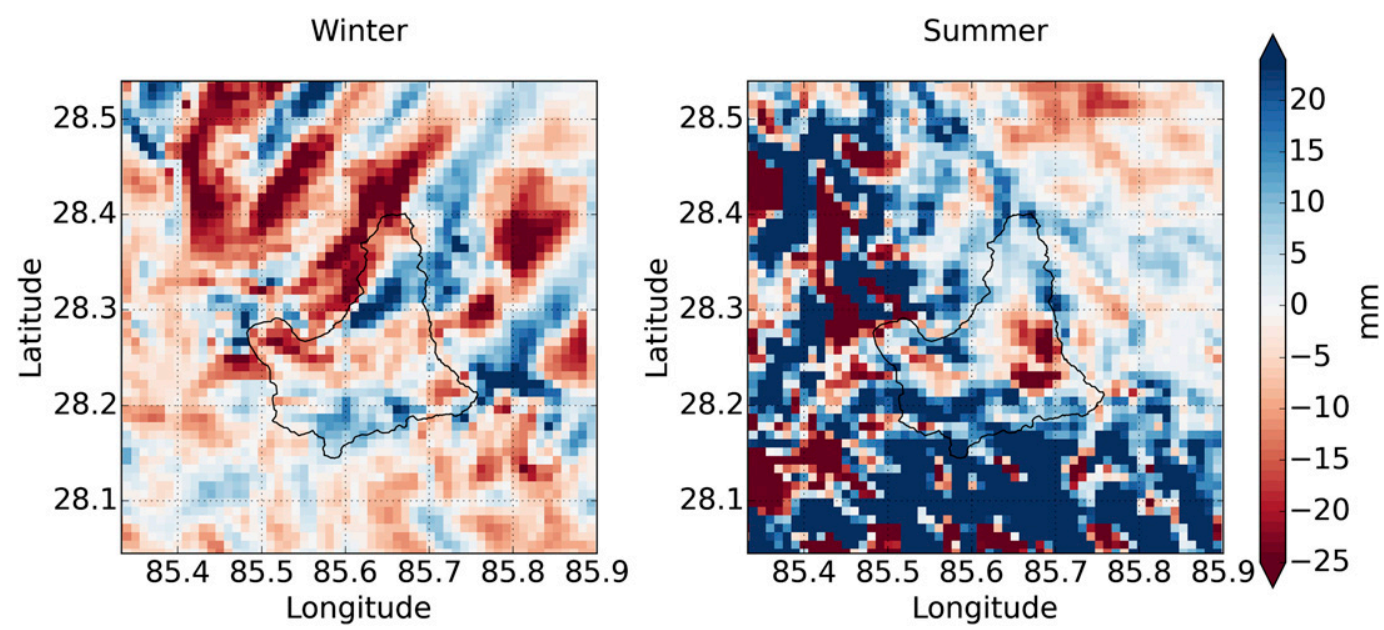

FIG. 6. The difference in total accumulated precipitation over 10 days between D3 and D4 (D4 minus D3) for the (left) winter and (right) summer periods. The 500-m grid-spacing cells were resampled onto a $1-\mathrm{km}$ grid to compare the different grid spacings. The black contour indicates the catchment outline. The topography of the domain is visible in Fig. 1.

found, for example, a Pearson correlation coefficient between 0.2 and 0.6 for daily precipitation at a resolution of $30 \mathrm{~km}$ in the Pacific-Andean region. Norris et al. (2017) looked in detail at precipitation patterns with WRF (grid spacing of $6.67 \mathrm{~km}$ ) in the Himalayas. They found WRF is accurate in the timing of winter storms on the windward slopes of the Himalayas, but that the more complex flow patterns forming further into the mountains are not represented correctly by the model. In accordance, the correlations of the time series of daily precipitation through winter vary between 0.13 and 0.82 , and the difference between low- (below $3 \mathrm{~km}$, correlation of 0.78 ) and high-elevation (correlation of 0.41 ) stations is large. In this research, 3-hourly averaged data are used rather than the commonly used daily averaged data (e.g., Ochoa et al. 2014; Norris et al. 2017). However, since our simulation period is relatively short, the averaging window cannot be increased.

The stations used for the statistics are concentrated in the lower parts of the valley; therefore, any improvement in the higher-elevated parts $(>5500 \mathrm{~m})$ cannot be evaluated. Especially in the winter period, the 500-m grid spacing reveals more detailed precipitation patterns at higher altitudes and shows that the precipitation distribution in winter is driven by the interaction with topography. The statistics in Table 5 are performed with
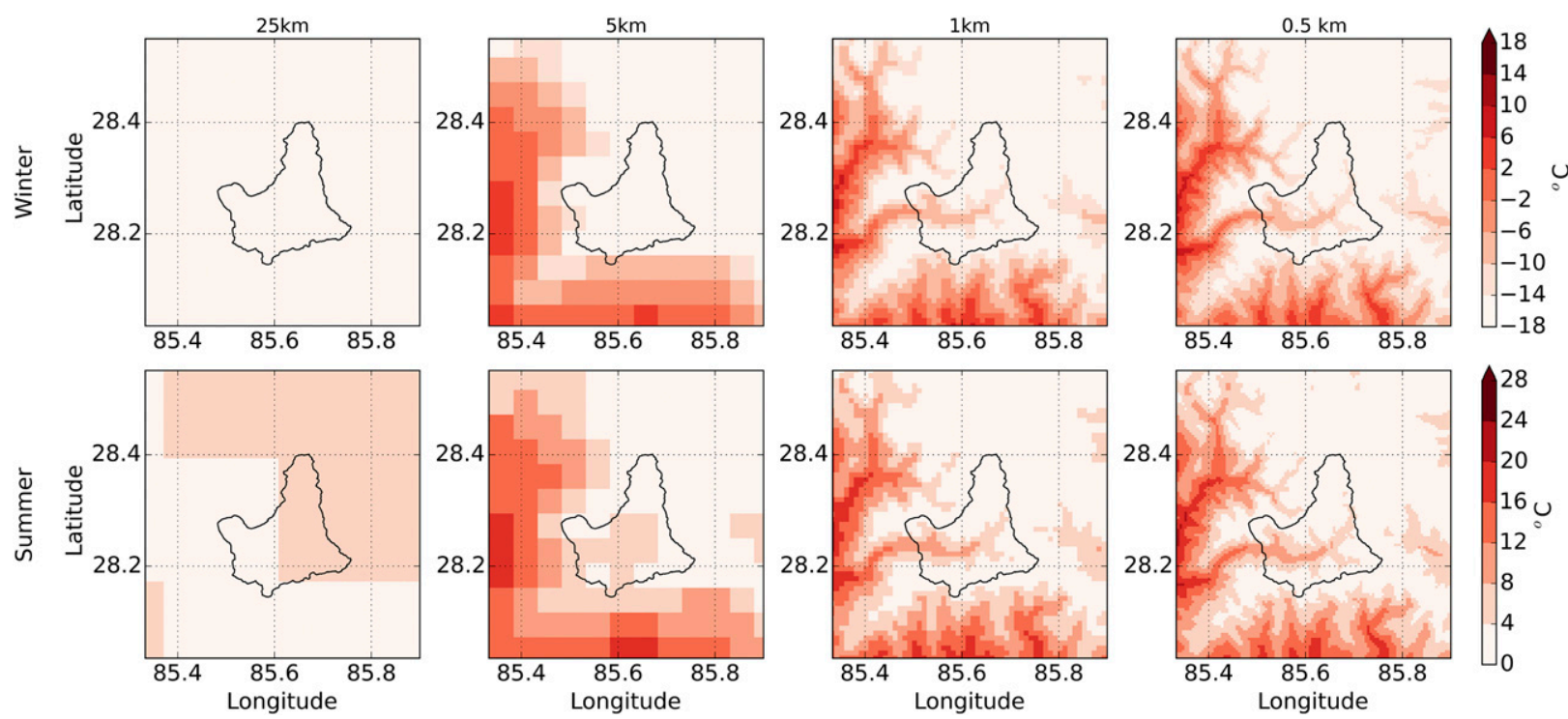

FIG. 7. As in Fig. 5, but for the 2-m air temperature. 

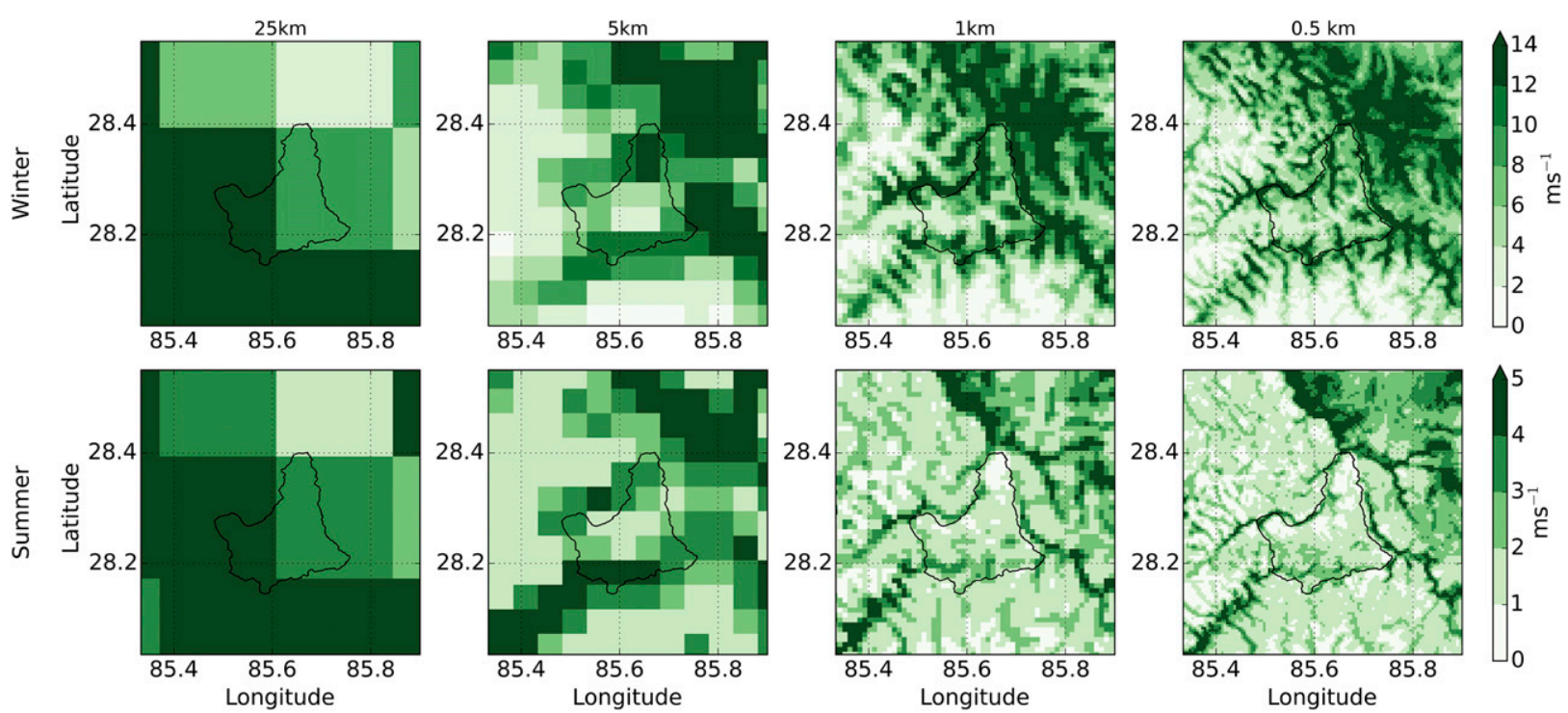

FIG. 8. As in Fig. 5, but for the 10-m wind speed.

uncorrected observations, but during winter the undercatch of snow plays a major role and complicates model evaluation. The role of undercatch of snow will be discussed in section $3 \mathrm{e}$.

\section{d. Optimal model configuration}

The 500-m grid spacing in combination with the FAO land use dataset and a spinup time of 1 day had the closest agreement with observations (EXP2, D4). The statistics of these experiments are shown in Table 5 and discussed in the previous section. In Figs. 9 and 10, the temporal evolution of the 2-m air temperature and precipitation (Figs. 9a, 10a), 10-m wind speed (Figs. 9b, $10 \mathrm{~b})$, the total accumulated precipitation compared to observations (Figs. 9c, 10c), and the temporal evolution of the snow depth (Figs. 9d, 10d) are given for the winter and summer period, respectively, averaged over all available stations. In the supplementary material, a comparison between the simulations and measurements is shown for three individual stations for precipitation, temperature, and wind speed. The general behavior of the temperature evolution is captured by WRF; however, an average cold temperature bias during winter and summer of $4.8^{\circ}$ and $1.5^{\circ} \mathrm{C}$, respectively, is present at the station locations in D4. Increasing the spatial resolution from $1 \mathrm{~km}$ to $500 \mathrm{~m}$ does decrease the cold bias by $3^{\circ}$ and $1^{\circ} \mathrm{C}$ for the winter and summer period, respectively. The cold bias could be exacerbated by a similar bias in the ERA-Interim boundary conditions (Dee et al. 2011), inaccuracies in the modeled terrain height, or the radiation scheme. The radiation scheme is tuned for lower elevations, since there are generally more stations at lower altitudes available for verification (Liu et al. 2008). A cold bias is a common issue in WRF (Kleczek et al. 2014; Steeneveld et al. 2008; Hu et al. 2010; García-Díez et al. 2013). Kleczek et al. (2014) tested the performance of seven PBL schemes for flat terrain in the Netherlands and found WRF underestimates the 2-m air temperature by $2^{\circ} \mathrm{C}$ during daytime and $4^{\circ} \mathrm{C}$ during nighttime. Since errors differ seasonally and increase with complex terrain, errors in our simulations are expected to be larger than in simulations over flat terrain (Liu et al. 2008). The 2-m air temperature is also sensitive to the selected land surface scheme (Jin et al. 2010).

The timing of the precipitation events is captured better during winter $(\mathrm{RI}=0.46)$ than in summer $(\mathrm{RI}=$ $0.09)$. In winter, a stratiform type of precipitation is generally present, while in summer relatively shortduration and high-intensity monsoon showers occur, which are more difficult to reproduce. The measured precipitation signal on 17 February 2014 appears to be caused by snowmelt in the tipping buckets and is therefore not a mismatch between the model and the observations (Fig. 9a). When excluding the period after 17 February, the RI and $r$ values are higher during winter in D4 (RI $=0.90$ and $r=0.6)$. During the summer (winter) period, the total accumulated precipitation of stations above $4600 \mathrm{~m}$ is underestimated (overestimated) by WRF by $57 \%$ (330\%) and does (does not) show a height dependence as at the lower-altitude stations (Figs. 9c, 10c). The lower-altitude stations overestimate precipitation during summer (Fig. 10c). WRF also shows snowfall in summer, which was not observed and could be caused by the cold bias in WRF (Fig. 10d). 
A.)
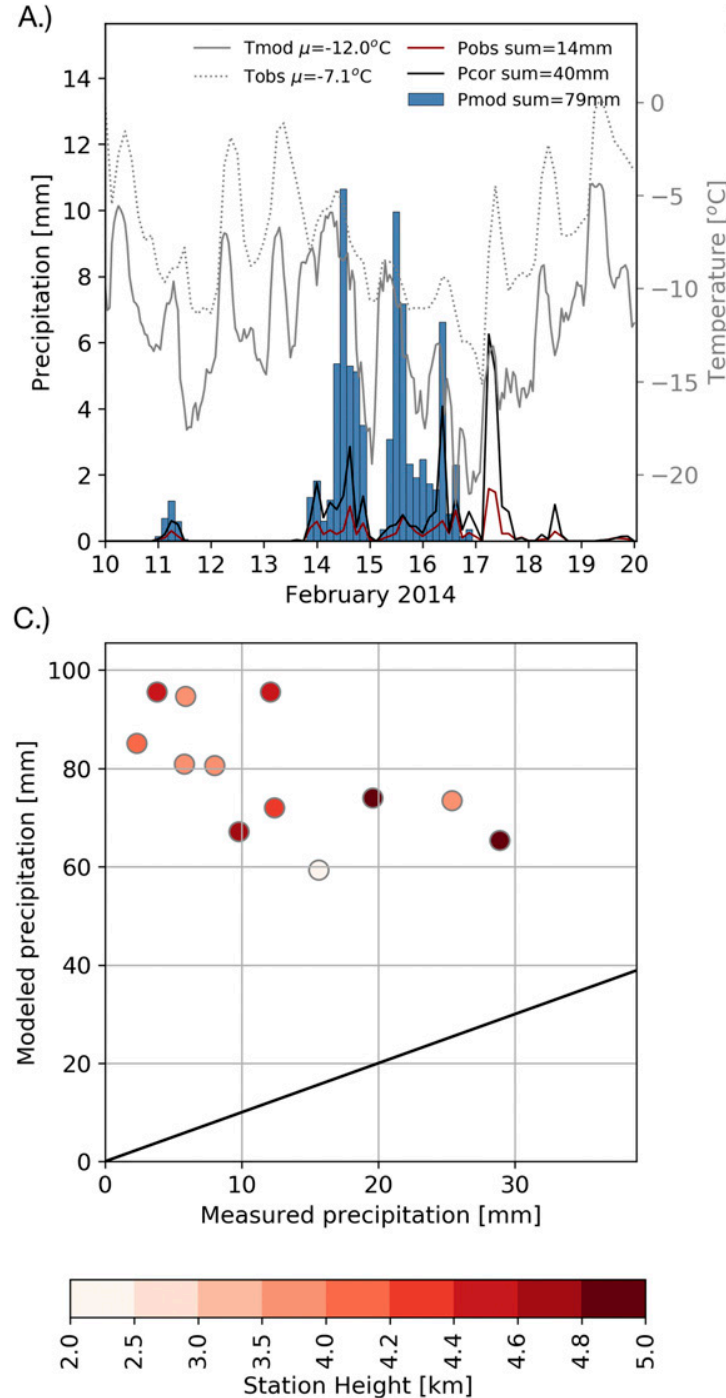

B.)

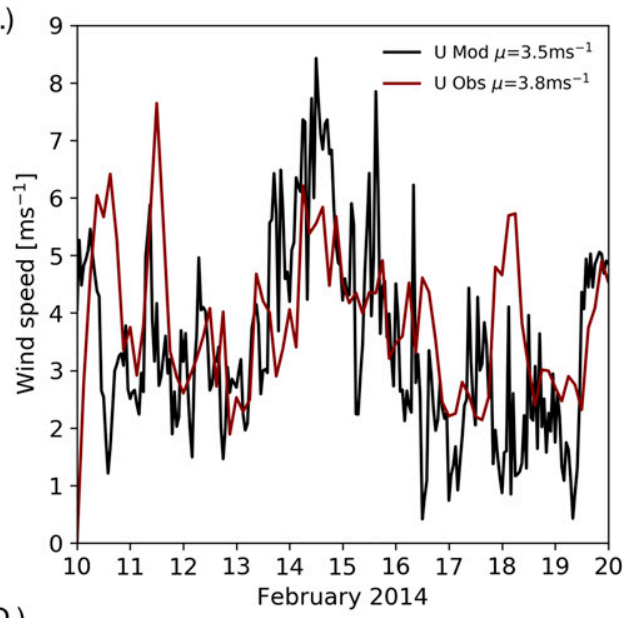

D.)

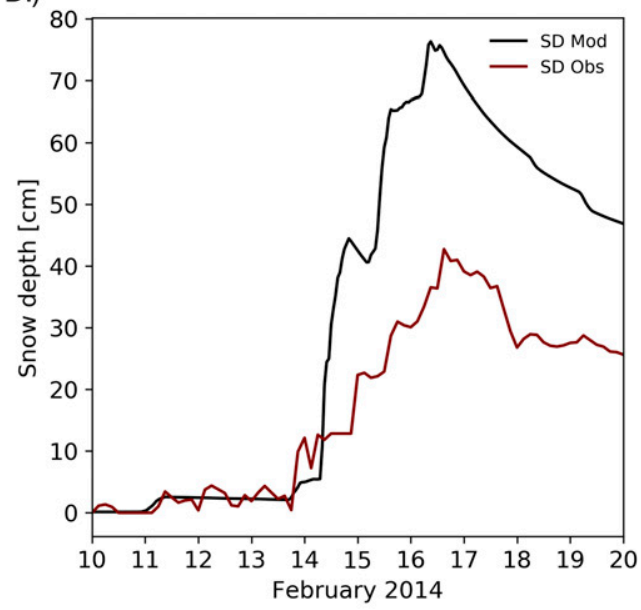

FIG. 9. Results of EXP2 for the winter period of D4: (a) modeled (solid gray line) and observed (dashed gray line) 2-m air temperature, modeled precipitation (blue bars), uncorrected observed precipitation (red line), and corrected observed precipitation (black line); (b) the 10-m observed (red line) and modeled (black line) wind speed; (c) the total accumulated precipitation colored by elevation, and (d) the modeled (black line) and observed (red line) snow depth. The data in (a), (b), and (d) are 3-hourly averaged and are averaged over all available stations.

During the winter simulation, WRF greatly overestimates the total accumulated precipitation at all measurement stations (between 37 and $92 \mathrm{~mm}$ ), which is not height dependent, as can be seen in Fig. 9c. However, the underestimation of measured precipitation due to undercatch of snow likely plays an important role in the winter season, as will be discussed in the following section.

\section{e. Correction for undercatch of snow}

To estimate the amount of undercatch of snow by the measurement stations, the observed precipitation of the two pluviometers is compared to the observed snow depth measured at the same two pluviometers. A fresh snow density of $200 \mathrm{~kg} \mathrm{~m}^{-3}$ to snow water equivalent (SWE) is used to convert changes in snow depth (Cuffey and Paterson 2010). Averaged over the two available pluviometers in winter, the observed precipitation and total increase in snow depth were 1.6 and $40 \mathrm{~cm}(8 \mathrm{~cm}$ SWE), respectively. The discrepancy suggests that the precipitated snow measured by the pluviometers is underestimated by a factor of 5 compared to the snow depth, neglecting the uncertainties in the latter field (e.g., snow density and melt, compaction, transport by 
A.)

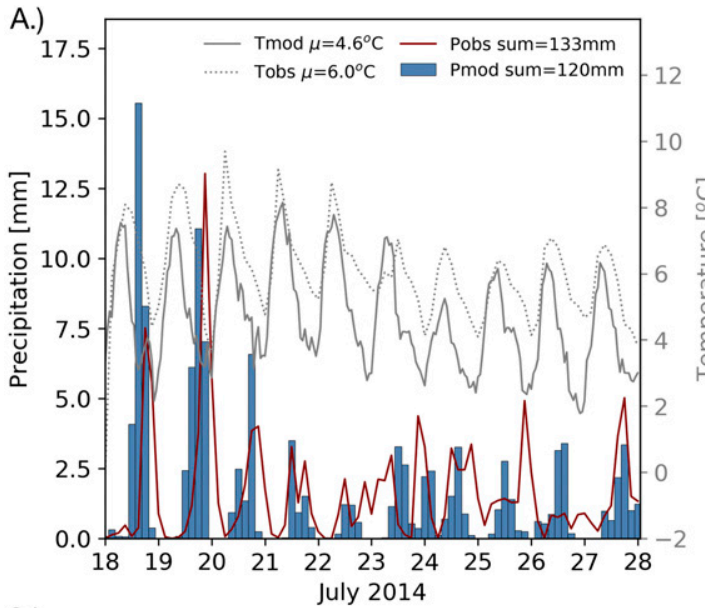

C.)
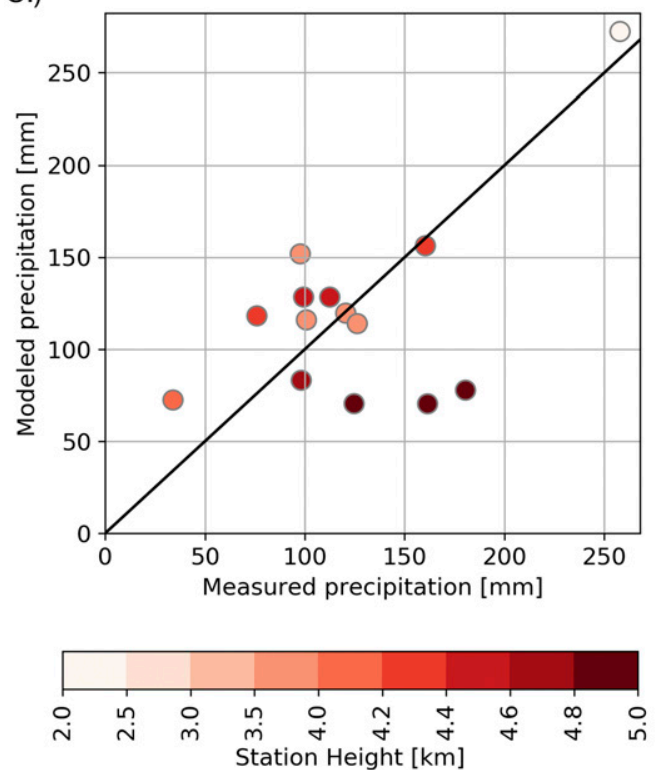

B.)

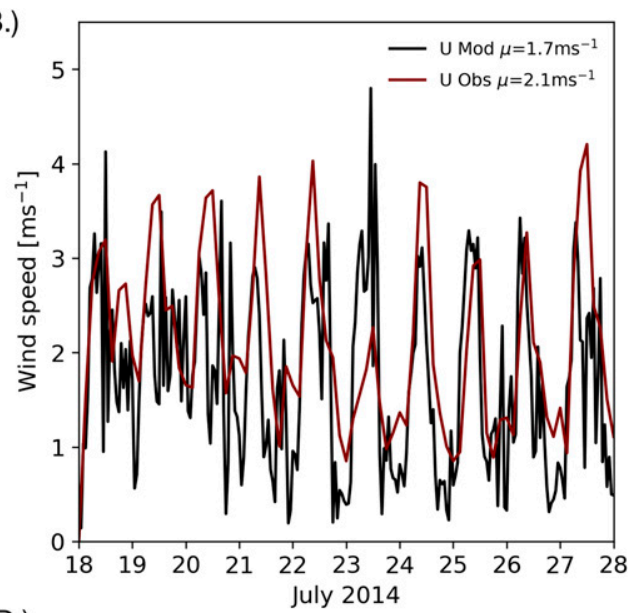

D.)

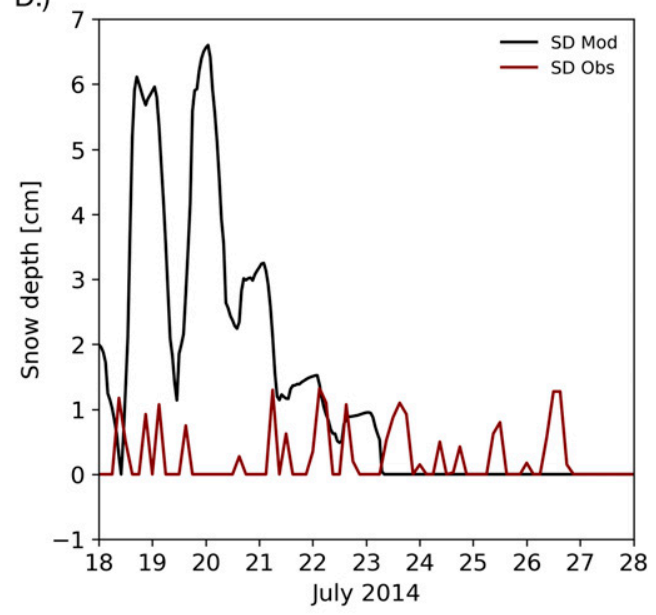

FIG. 10. Results of EXP2 for the summer period of D4: (a) modeled (solid gray line) and observed (dashed gray line) 2-m air temperature, modeled precipitation (blue bars), and uncorrected observed precipitation (red line); (b) the 10-m observed (red line) and modeled (black line) wind speed; (c) the total accumulated precipitation colored by elevation, and (d) the modeled (black line) and observed (red line) snow depth. The data in (a), (b), and (d) are 3-hourly averaged and are averaged over all available stations.

wind). WRF models $7.3 \mathrm{~cm}$ of SWE averaged over the two grid points of the locations of the pluviometers. This value is consistent with the amount of snow derived from snow depth measurements and supports that undercatch of the pluviometer may contribute significantly to an underestimation. For a similar region in the Himalayas, Norris et al. (2017) also found an overestimation of a factor of 2-5 by WRF compared to observed precipitation, which is also likely caused by the undercatch of snow. Figure 11 shows the impact of applying the snow correction factors to the Kyanging AWS (Table 1) for both assuming dry snow (upper limit) and mixed snow (lower limit). As a result, the uncertainty of the corrected snow amounts due to the type of snow is delineated by the gray-shaded area between the two curves. These correction factors are applied on the observed precipitation, wind, and temperature from the AWS in Kyanging. The correction has a large influence on the total measured accumulated precipitation. The amount of uncorrected precipitation is $25 \mathrm{~mm}$, while the corrected values are 76 and $48 \mathrm{~mm}$ for dry snow and a mixture of wet and dry snow, respectively. The correction results in a much closer match with the WRF simulations $(73 \mathrm{~mm})$. 


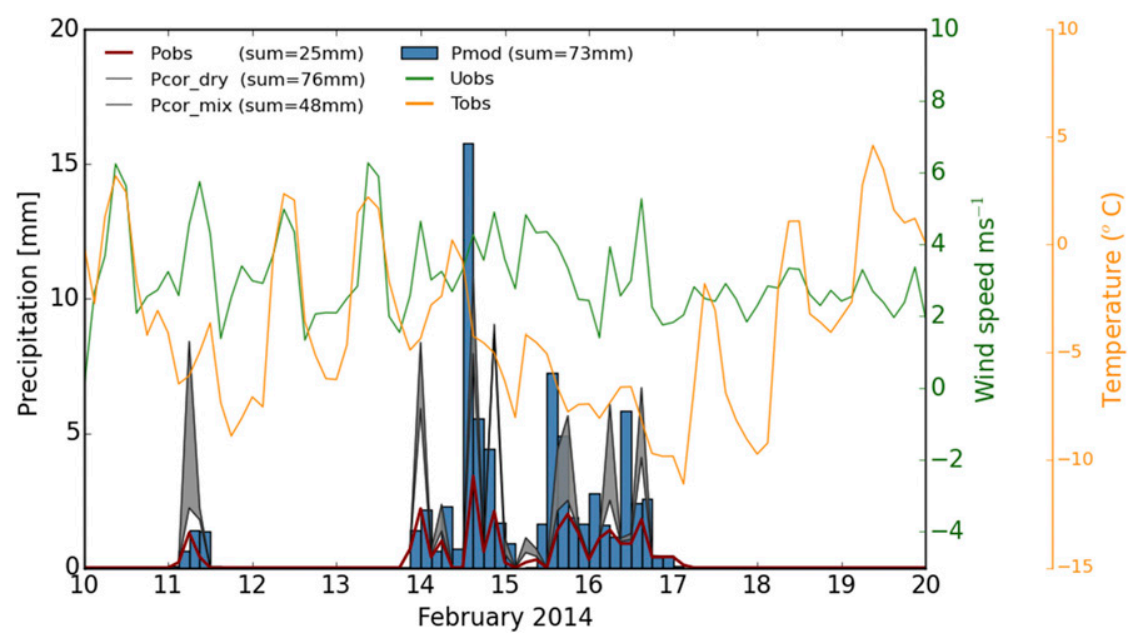

FIG. 11. The modeled precipitation (blue bars), observed 2-m air temperatures (yellow), 10-m observed wind speed (green), uncorrected observed precipitation (red line), and the corrected observed precipitation when assuming dry snow (upper black line) and a mixture of snow (lower black line) for the measurement station of Kyanging. The gray color indicates the uncertainty of the corrected snow amounts due to the type of snow.

The wind speed is only measured by the AWS, and in order to apply the correction factor to all measurement stations for a spatial indication of the undercatch of snow, the modeled wind speed and temperature are used. Since temperatures are consistently below zero, the dry correction factor is used for all stations (black line in Fig. 9a). Averaged over all stations, the observed, corrected, and modeled precipitation amounts are 14, 40 , and $79 \mathrm{~mm}$, respectively. The correction does not entirely close the gap with model results, and there could be several explanations. The modeled wind speed could be underestimated at the steep slopes in $\mathrm{D} 4$ caused by the representation of topography. Second, the snow measurements are only corrected for the wind speed, but also other uncertainties are present. For example, evaporation takes place in tipping buckets when the rainfall intensity is low and the conditions are favorable for evaporation. Because of this loss of water, it is not certain if all precipitation is measured by the tipping buckets. Third, the melting peak at 17 February indicates that the buckets of the tipping buckets were likely filled, whereby no new snow is registered and the accumulated precipitation is underestimated. For solid precipitation the uncertainties are larger than for liquid precipitation, since snow accumulates in the bucket and is only recorded when it melts, which causes a delay in the measurements. Additionally, snow can be blown out of the bucket, and the amount cannot exceed the volume of the bucket. For the pluviometers these problems do not occur, since these are larger and measure every minute. Another source of uncertainty of $\approx 4 \%$ is present in tipping buckets during high-intensity rainfall, whereby precipitation is splashed out the bucket (Orr et al. 2017). For quantification of errors in the future, we installed time-lapse cameras in the field campaign of spring 2017 to identify if precipitation events match with the records. On top of all the measurement uncertainties, the cold bias in WRF can also lead to more snow and increase the bias with this positive feedback.

\section{Conclusions}

In this study we modeled a summer and winter period for a high-altitude catchment in Nepal (Langtang) with a grid spacing down to $500 \mathrm{~m}$ in WRF and compared the results to observations of precipitation, 2-m air temperature, and 10-m wind speed. The sensitivity of the results to the land use and the spinup time in WRF were also investigated.

The largest improvements were observed when decreasing the grid spacing to $500 \mathrm{~m}$ in the $2-\mathrm{m}$ temperature and 10-m wind speed. The 2-m temperature shows a large negative bias in both periods, which decreases with increasing resolutions [from $8.9^{\circ} \mathrm{C}\left(3.3^{\circ} \mathrm{C}\right)$ in $\mathrm{D} 2$ to $4.8^{\circ} \mathrm{C}$ $\left(1.5^{\circ} \mathrm{C}\right.$ ) in winter (summer) in the 500 -m grid spacing domain]. Simulated precipitation improves mostly in the higher-elevated parts of the valley, with values at the higher measurement stations $(>4600 \mathrm{~m})$ underestimated (overestimated) significantly in summer (winter) by $57 \%(330 \%)$. In the $500-\mathrm{m}$ grid spacing domain, more orographically forced precipitation is 
modeled at higher elevations than in the coarser domains. Currently available gridded precipitation products underestimate precipitation in this region (Immerzeel et al. 2015), and we show that increasing the spatial resolution contributes to more realistic amounts and patterns in complex terrain.

The influence of the land use on the amount of precipitation is large in summer, since it affects the latent heat flux. In this simulated summer (winter) period, the FAO land use dataset results in a decrease in precipitation averaged over the 1-km grid spacing domain of $10 \%(0 \%)$, which shows the importance of correctly specifying this field during the monsoon. Simulations are also sensitive to the spinup time (especially in the summer period), without a clear trend with increasing length. We found a spinup time of $24 \mathrm{~h}$ gave the highest correlations of precipitation, 2-m air temperature, and $10-\mathrm{m}$ wind speed compared to the periods of $12 \mathrm{~h}, 3$ days, and 5 days.

The evaluation of the simulations was done with relatively low elevation stations, and the sparsity of stations above $5500 \mathrm{~m}$ prevents a full evaluation of the distributed fields. More high-elevated stations are needed for a thorough validation, but the results from low-elevation stations are promising. We showed that the undercatch of snow complicates model evaluation for the winter period. Relationships of undercatch of snow with wind speed and temperature (Thériault et al. 2012) were used to determine the corrected amount of snow. For a 10-day period in winter, the undercatch of dry snow $(51 \mathrm{~mm})$ contributed strongly to the discrepancy between the model $(73 \mathrm{~mm})$ and uncorrected $(25 \mathrm{~mm})$ measurements. Applying the correction factor to all measurement stations with the modeled wind speed and temperature is difficult, since the wind speed at steep slopes is likely too low.

To our knowledge, this study is the first subkilometer investigation of a High Mountain Asian catchment with WRF and shows that there is an improved agreement with observations compared to the kilometer scale (except for winter precipitation). Modest improvements were observed when the resolution was increased to $500 \mathrm{~m}$, suggesting that, in combination with future improvements to atmospheric models for applications in complex terrain, subkilometer grid spacing may more accurately resolve catchment-scale meteorological variability and therefore the resulting glacio-hydrological changes. An important avenue of future research would be to evaluate possible improvements when the resolution is further refined and LES modeling is used; however, this is computationally unfeasible for interannual investigations.
Our results increase confidence in the performance of WRF at high resolution and demonstrate the importance of reasonably accurate surface boundary conditions for simulating precipitation. It resolves weather parameters more explicitly with altitude, provides a better match with observations, and is still computationally feasible. Furthermore, the results suggest that future modeling studies in complex terrain should consider subkilometer grid for accurately resolving local meteorological variability.

Acknowledgments. This project has received funding from the European Research Council (ERC) under the European Union Horizon 2020 research and innovation programme (Grant Agreement 676819) and the Netherlands Organization for Scientific Research under the Innovational Research Incentives Scheme VIDI (Grant Agreement 016.181.308). E. Collier was supported by the German Research Foundation (DFG) Grant MO 2869/1-1. ICIMOD is acknowledged for the observational data of Yala and Kyanging stations. Supercomputing resources were financially supported by NWO and provided by SURFsara (www.surfsara.nl) on the Cartesius cluster.

\section{REFERENCES}

Arnold, D., and Coauthors, 2012: High resolution modelling in complex terrain: Report on the HiRCoT 2012 Workshop, Vienna, 21-23 February 2012. BOKU-Met Rep. 21, 52 pp., https:// meteo.boku.ac.at/report/BOKU-Met_Report_21_online.pdf.

Bookhagen, B., and D. W. Burbank, 2010: Toward a complete Himalayan hydrological budget: Spatiotemporal distribution of snowmelt and rainfall and their impact on river discharge. J. Geophys. Res. Earth Surf., 115, F03019, https://doi.org/ 10.1029/2009JF001426.

Cheng, F.-Y., Y.-C. Hsu, P.-L. Lin, and T.-H. Lin, 2013: Investigation of the effects of different land use and land cover patterns on mesoscale meteorological simulations in the Taiwan area. J. Appl. Meteor. Climatol., 52, 570-587, https:// doi.org/10.1175/JAMC-D-12-0109.1.

Collier, E., and W. W. Immerzeel, 2015: High-resolution modeling of atmospheric dynamics in the Nepalese Himalaya. J. Geophys. Res. Atmos., 120, 9882-9896, https://doi.org/ 10.1002/2015JD023266.

Cuffey, K. M., and W. S. B. Paterson, 2010: The Physics of Glaciers. 4th ed. Academic Press, 704 pp.

Dee, D. P., and Coauthors, 2011: The ERA-Interim reanalysis: Configuration and performance of the data assimilation system. Quart. J. Roy. Meteor. Soc., 137, 553-597, https://doi.org/ 10.1002/qj.828.

Dimitrova, R., H. Fernando, Z. Silver, L. Leo, C. Hocut, T. Zsedrovits, and S. Di Sabatino, 2014: Modification of the Yonsei University boundary layer scheme in the WRF Model for stable conditions. Sixth Int. Conf. on Harmonisation within Atmospheric Dispersion Modelling for Regulatory Purposes, Varna, Bulgaria, Bulgarian Academy of Sciences, 330-335, http://www.harmo.org/Conferences/Proceedings/_Varna/ publishedSections/H16-095-Dimitrova-EA.pdf. 
— Z. Silver, T. Zsedrovits, C. M. Hocut, L. S. Leo, S. Sabatino, and H. J. Fernando, 2016: Assessment of planetary boundarylayer schemes in the weather research and forecasting mesoscale model using MATERHORN field data. Bound.-Layer Meteor., 159, 589-609, https://doi.org/10.1007/s10546-015-0095-8.

FAO, 2017: Land cover map. http://www.fao.org/geonetwork/srv/ en/main.home?uuid=46d3c2ef-72c3-4f96-8e32-40723cd1847b.

García-Díez, M., J. Fernández, L. Fita, and C. Yagüe, 2013: Seasonal dependence of WRF model biases and sensitivity to PBL schemes over Europe. Quart. J. Roy. Meteor. Soc., 139, 501514, https://doi.org/10.1002/qj.1976.

Giovannini, L., G. Antonacci, D. Zardi, L. Laiti, and L. Panziera, 2014: Sensitivity of simulated wind speed to spatial resolution over complex terrain. Energy Procedia, 59, 323-329, https:// doi.org/10.1016/j.egypro.2014.10.384.

Goodison, B. E., P. Louie, and D. Yang, 1998: WMO solid precipitation intercomparison. Instruments and Observing Methods Rep. 67, WMO/TD-872, 212 pp., https://www.wmo. int/pages/prog/www/IMOP/publications/IOM-67-solid-precip/ WMOtd872.pdf.

Hong, S.-Y., and J. Dudhia, 2012: Next-generation numerical weather prediction: Bridging parameterization, explicit clouds, and large eddies. Bull. Amer. Meteor. Soc., 93, ES6ES9, https://doi.org/10.1175/2011BAMS3224.1.

_- Y. Noh, and J. Dudhia, 2006: A new vertical diffusion package with an explicit treatment of entrainment processes. Mon. Wea. Rev., 134, 2318-2341, https://doi.org/10.1175/MWR3199.1.

Horvath, K., D. Koracin, R. Vellore, J. Jiang, and R. Belu, 2012: Sub-kilometer dynamical downscaling of near-surface winds in complex terrain using WRF and MM5 mesoscale models. J. Geophys. Res., 117, D11111, https://doi.org/10.1029/ 2012JD017432.

Hu, X.-M., J. W. Nielsen-Gammon, and F. Zhang, 2010: Evaluation of three planetary boundary layer schemes in the WRF Model. J. Appl. Meteor. Climatol., 49, 1831-1844, https://doi.org/ 10.1175/2010JAMC2432.1.

Iacono, M. J., J. S. Delamere, E. J. Mlawer, M. W. Shephard, S. A. Clough, and W. D. Collins, 2008: Radiative forcing by long-lived greenhouse gases: Calculations with the AER radiative transfer models. J. Geophys. Res., 113, D13103, https:// doi.org/10.1029/2008JD009944.

Immerzeel, W. W., L. P. Van Beek, and M. F. Bierkens, 2010: Climate change will affect the Asian water towers. Science, 328, 1382-1385, https://doi.org/10.1126/science.1183188.

-, L. Petersen, S. Ragettli, and F. Pellicciotti, 2014: The importance of observed gradients of air temperature and precipitation for modeling runoff from a glacierized watershed in the Nepalese Himalayas. Water Resour. Res., 50, 2212-2226, https://doi.org/10.1002/2013WR014506.

— N. Wanders, A. Lutz, J. Shea, and M. Bierkens, 2015: Reconciling high-altitude precipitation in the upper Indus basin with glacier mass balances and runoff. Hydrol. Earth Syst. Sci., 19, 4673, https://doi.org/10.5194/hess-19-4673-2015.

Jankov, I., W. A. Gallus Jr., M. Segal, and S. E. Koch, 2007: Influence of initial conditions on the WRF-ARW model QPF response to physical parameterization changes. Wea. Forecasting, 22, 501-519, https://doi.org/10.1175/WAF998.1.

Jin, J., N. L. Miller, and N. Schlegel, 2010: Sensitivity study of four land surface schemes in the WRF Model. Adv. Meteor., 2010, 167436, https://doi.org/10.1155/2010/167436.

Kain, J. S., 2004: The Kain-Fritsch convective parameterization: An update. J. Appl. Meteor., 43, 170-181, https://doi.org/ 10.1175/1520-0450(2004)043<0170:TKCPAU > 2.0.CO;2.
Kleczek, M. A., G.-J. Steeneveld, and A. A. Holtslag, 2014: Evaluation of the weather research and forecasting mesoscale model for GABLS3: Impact of boundary-layer schemes, boundary conditions and spin-up. Bound.-Layer Meteor., 152, 213-243, https://doi.org/10.1007/s10546-014-9925-3.

Kraaijenbrink, P., M. Bierkens, A. Lutz, and W. Immerzeel, 2017: Impact of a global temperature rise of 1.5 degrees Celsius on Asia's glaciers. Nature, 549, 257, https://doi.org/10.1038/ nature23878.

Liu, J., and R. Chen, 2016: Discriminating types of precipitation in Qilian Mountains, Tibetan Plateau. J. Hydrol. Reg. Stud., 5, 20-32, https://doi.org/10.1016/j.ejrh.2015.11.013.

Liu, Y., and Coauthors, 2008: The operational mesogammascale analysis and forecast system of the U.S. Army Test and Evaluation Command. Part II: Interrange comparison of the accuracy of model analyses and forecasts. J. Appl. Meteor. Climatol., 47, 1093-1104, https://doi.org/10.1175/ 2007JAMC1654.1.

Maussion, F., D. Scherer, R. Finkelnburg, J. Richters, W. Yang, and T. Yao, 2011: WRF simulation of a precipitation event over the Tibetan Plateau, China-An assessment using remote sensing and ground observations. Hydrol. Earth Syst. Sci., 15, 1795, https://doi.org/10.5194/hess-15-1795-2011.

,,-- T. Mölg, E. Collier, J. Curio, and R. Finkelnburg, 2014: Precipitation seasonality and variability over the Tibetan Plateau as resolved by the High Asia Reanalysis. J. Climate, 27, 1910-1927, https://doi.org/10.1175/JCLI-D-13-00282.1.

Morrison, H., G. Thompson, and V. Tatarskii, 2009: Impact of cloud microphysics on the development of trailing stratiform precipitation in a simulated squall line: Comparison of oneand two-moment schemes. Mon. Wea. Rev., 137, 991-1007, https://doi.org/10.1175/2008MWR2556.1.

Niu, G.-Y., and Coauthors, 2011: The community Noah land surface model with multiparameterization options (Noah-MP): 1 . Model description and evaluation with local-scale measurements. J. Geophys. Res., 116, D12109, https://doi.org/10.1029/ 2010JD015139.

Norris, J., L. M. Carvalho, C. Jones, F. Cannon, B. Bookhagen, E. Palazzi, and A. A. Tahir, 2017: The spatiotemporal variability of precipitation over the Himalaya: Evaluation of oneyear WRF Model simulation. Climate Dyn., 49, 2179-2204, https://doi.org/10.1007/s00382-016-3414-y.

Ochoa, A., L. Pineda, P. Crespo, and P. Willems, 2014: Evaluation of TRMM 3B42 precipitation estimates and WRF retrospective precipitation simulation over the Pacific-Andean region of Ecuador and Peru. Hydrol. Earth Syst. Sci., 18, 3179, https:// doi.org/10.5194/hess-18-3179-2014.

Orr, A., C. Listowski, M. Couttet, E. Collier, W. Immerzeel, P. Deb, and D. Bannister, 2017: Sensitivity of simulated summer monsoonal precipitation in Langtang Valley, Himalaya to cloud microphysics schemes in WRF. J. Geophys. Res. Atmos., 122, 6298-6318, https://doi.org/ 10.1002/2016JD025801.

Paulson, C. A., 1970: The mathematical representation of wind speed and temperature profiles in the unstable atmospheric surface layer. J. Appl. Meteor., 9, 857-861, https://doi.org/ 10.1175/1520-0450(1970)009<0857:TMROWS $>2.0$. CO; 2 .

Qiu, J., 2008: China: The third pole. Nature, 454, 393-396, https:// doi.org/10.1038/454393a.

Rasmussen, R., and Coauthors, 2011: High-resolution coupled climate runoff simulations of seasonal snowfall over Colorado: A process study of current and warmer climate. J. Climate, 24, 3015-3048, https://doi.org/10.1175/2010JCLI3985.1. 
Reinert, D., and V. Wirth, 2009: A new large-eddy simulation model for simulating air flow and warm clouds above highly complex terrain. Part II: The moist model and its application to banner clouds. Bound.-Layer Meteor., 133, 113-136, https:// doi.org/10.1007/s10546-009-9419-x.

Román-Cascón, C., G. Steeneveld, C. Yagüe, M. Sastre, J. Arrillaga, and G. Maqueda, 2016: Forecasting radiation fog at climatologically contrasting sites: Evaluation of statistical methods and WRF. Quart. J. Roy. Meteor. Soc., 142, 10481063, https://doi.org/10.1002/qj.2708.

Rousseau, D., 1980: A new skill score for the evaluation of yes/no forecasts. Proc. WMO Symp. on Probabilistic and Statistical Methods in Weather Forecasting, Nice, France, WMO, 167174.

Skamarock, W. C., 2004: Evaluating mesoscale NWP models using kinetic energy spectra. Mon. Wea. Rev., 132, 3019-3032, https://doi.org/10.1175/MWR2830.1.

_ , and J. B. Klemp, 2008: A time-split nonhydrostatic atmospheric model for weather research and forecasting applications. J. Comput. Phys., 227, 3465-3485, https://doi.org/ 10.1016/j.jcp.2007.01.037.

Steeneveld, G., T. Mauritsen, E. De Bruijn, J. Vilà-Guerau de Arellano, G. Svensson, and A. Holtslag, 2008: Evaluation of limited-area models for the representation of the diurnal cycle and contrasting nights in CASES-99. J. Appl. Meteor. Climatol., 47, 869-887, https://doi.org/10.1175/2007JAMC1702.1.

Talbot, C., E. Bou-Zeid, and J. Smith, 2012: Nested mesoscale large-eddy simulations with WRF: Performance in real test cases. J. Hydrometeor., 13, 1421-1441, https://doi.org/10.1175/ JHM-D-11-048.1.

Thériault, J. M., R. Rasmussen, K. Ikeda, and S. Landolt, 2012: Dependence of snow gauge collection efficiency on snowflake characteristics. J. Appl. Meteor. Climatol., 51, 745-762, https:// doi.org/10.1175/JAMC-D-11-0116.1.

Wang, C., D. Wilson, T. Haack, P. Clark, H. Lean, and R. Marshall, 2012: Effects of initial and boundary conditions of mesoscale models on simulated atmospheric refractivity. J. Appl. Meteor. Climatol., 51, 115-132, https://doi.org/10.1175/JAMC-D-11012.1.

Whiteman, C. D., 2000: Mountain Meteorology: Fundamentals and Applications. Oxford University Press, 355 pp.

Wyngaard, J. C., 2004: Toward numerical modeling in the terra incognita. J. Atmos. Sci., 61, 1816-1826, https://doi.org/ 10.1175/1520-0469(2004)061<1816:TNMITT >2.0.CO;2.

Yao, T., and Coauthors, 2012: Third Pole Environment (TPE). Environ. Dev., 3, 52-64, https://doi.org/10.1016/j.envdev.2012. 04.002 .

Zängl, G., 2002: An improved method for computing horizontal diffusion in a sigma-coordinate model and its application to simulations over mountainous topography. Mon. Wea. Rev., 130, 1423-1432, https://doi.org/10.1175/1520-0493(2002)130<1423: AIMFCH $>2.0 . \mathrm{CO} ; 2$

Zhang, H., Z. Pu, and X. Zhang, 2013: Examination of errors in near-surface temperature and wind from WRF numerical simulations in regions of complex terrain. Wea. Forecasting, 28, 893-914, https://doi.org/10.1175/WAF-D-12-00109.1. 